\title{
北米スポーツマネジメント学会 2017 年度大会 \\ The North American Society for Sport management Conference 2017
}

\section{高田紘佑}

今回で 32 回目となる 2017 年北米スポーツマネジメント学会（North American Society for Sport Management：以下「NASSM」と略す）が、2017年 5 月 30 日から 6 月 3 日にかけて、米国コロラ ド州デンバーで開催された。NASSM の発表によると、研究発表への応募数は計 529 件であり、採 択に至ったのは 382 件（採択率 72.2\%）であった。最終的に、361 件の口頭発表やポスター発表が 行われた。一昨年度大会以前と比較すると、昨年度大会と同様に採択率の高い大会であった。

\section{研究分野別の研究動向}

はじめに、今大会では応募時に選択する研究分野が再編された。昨年度大会までは 15 の研究分 野から 1 つを選ぶ形式であったのに対し、今大会では「12 の研究分野」「44 の研究トピック」「15 の研究対象」からそれぞれ 1つずつ選択する形式となった。こちらの詳細については後述したい。

表 1 では、2017 年度大会で報告された研究発表の件数と割合を研究分野別に示し、参考用に 2016 年度の研究分野別発表数を記載している。前回大会と同様、マーケティング分野の研究発表 が最も多く、全体の $28.0 \%$ を占めた。次いで、マネジメント分野が $19.9 \%$ 、社会文化的側面に関す る分野の発表が $10.8 \%$ であった。発表件数の多い分野の傾向は 2016 年度大会と類似していた。

次に、研究分野の再編について見ていきたい。2017 年度大会から「施設・イベント（Facilities / Events)」と「開発のためのスポーツ（Sport for development）」を含む 3 分野が新設され、「組織論・ 組織文化 (Organizational theory / Culture)」「人材の多様性 (Diversity)」「専門的職業準備 (Professional preparation)」「スポーツ・ツーリズム（Sport tourism)」「倫理学（Ethics）」の 5 分野に関する選択肢 が無くなった（表 1)。しかしながら、これは研究応募時の分野に関する選択肢が見られなくなっ たということであり、これらの分野に関する研究が発表されなくなった訳ではない。

表 2 では、2017 年度大会における研究分野、研究トピック及び研究対象についてまとめた。す ると、同様の研究トピックでも異なる研究分野に属す発表が存在すると分かる。例えば、「多様性 (Diversity)」という研究トピックは、マーケティング分野とマネジメント分野の双方に見られ、研 究トピック「スポンサーシップ(Sponsorship)」は、マーケティング分野と施設・イベント分野に見 受けられる。スポーツマネジメントという学際的な分野の特徴が、ここでも指摘できる。

以下では、今大会での発表件数が最も多かったマーケティング分野と、近年注目を集める開発の ためのスポーツ分野の研究動向について記述する。

\section{1. マーケティング}

本大会では、マーケティング分野の研究として 101 題が発表された。研究トピックとしては消費 
表 12017 年度大会の研究分野別発表件数

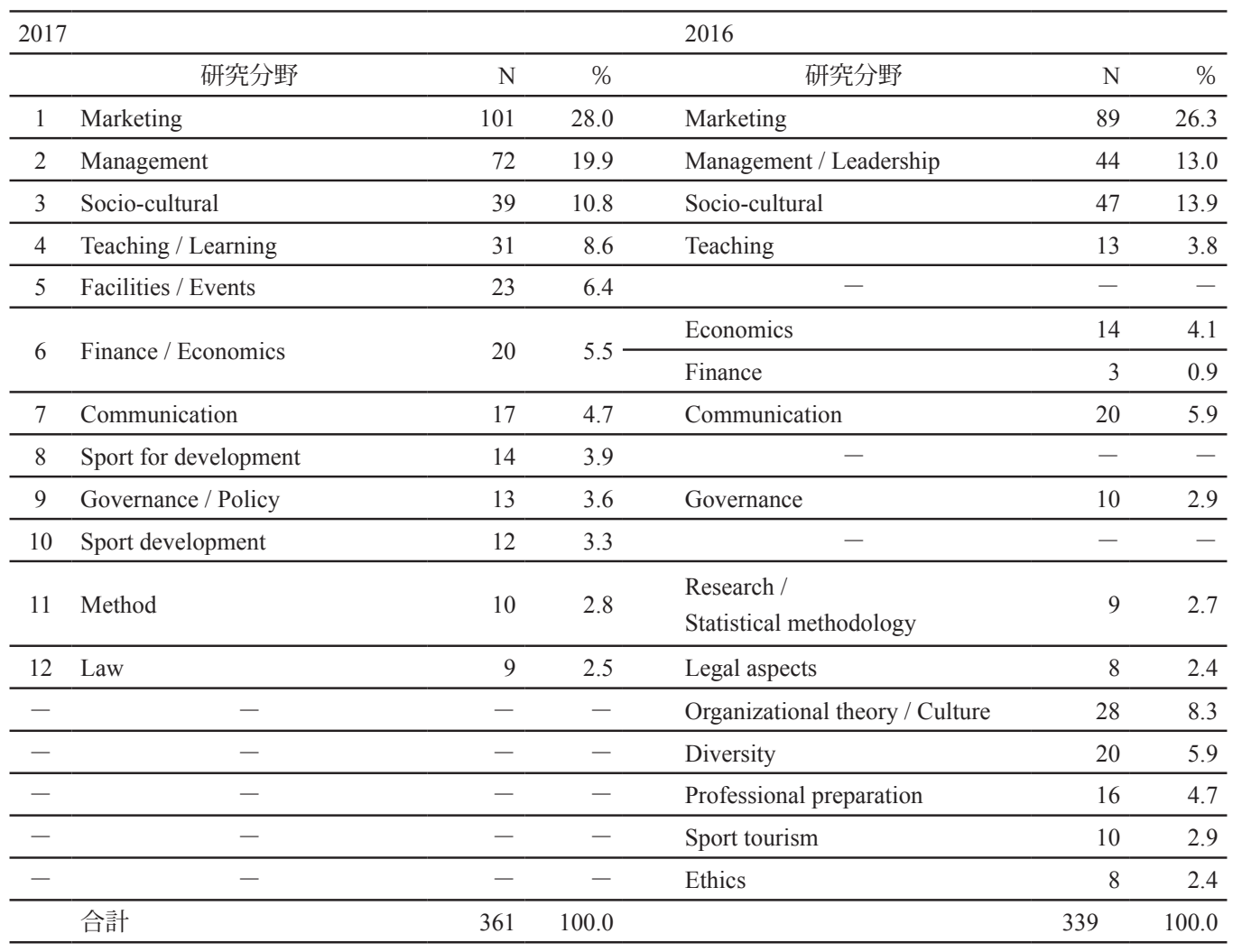

者行動（Consumer behavior）が 43 題と最も多く、ブランディング（Branding）が 12 題、スポンサ ーシップ（Sponsorship）が 11 題、モチベーション（Motivation）が 10 題と続いた。また、マーケ ティング分野の研究対象として最も多かったのはプロスポーツであり、38題が発表された。次いで、 大学スポーツが 11 題、エリートスポーツとアマチュアスポーツが各 6 題である。

ここでは、ブランディング (Branding) に関する発表について詳細に報告したい。学会では、ゴ ルフ大会やマイナーリーグのブランドエクイティといった研究 (Hanna et al., 2017; Lee et al., 2017) のみならず、学生スポーツアスリートの大学選択における大学のブランドに関する研究 (Medeiros and Chard, 2017）等が発表された。

中でも筆者が個人的に興味深かったのは、必ずしもスポーツイベントの開催が開催都市の国際的 イメージに好影響を与えるわけではない、ということを明らかにした研究（Heere et al., 2017）で あった。この研究は、ツール・ド・フランスの出発地点であるオランダのユトレヒトに着目して行 われ、調査は世界 9 カ国で実施された。調査対象は二群に分けられ、コントロール群はツール・ド・ フランスに関する情報を含まない冊子を、非コントロール群には同情報を含めた冊子が配布され、 その後に回答を得ている。9 力国全体の結果として統計的に有意な結果は見られなかったが、国別 に着目すると、フランスを含む 3 力国でネガティブな効果が見られた。特にフランスで見られたネ ガティブな反応について Heere et al.（2017）は、自国で開催されてきたイベントが他国（他都市） に奪われたように感じられるからではないかと説明している。

近年、オリンピックやサッカーワールドカップの開催是非に関して開催地域の住民から疑問が投 げかけられる場面も見受けられる。持続的なスポーツイベントの開催に関する学術界からの貢献が、 
表 22017 年度大会における研究分野・研究トピック・研究対象

\begin{tabular}{|c|c|c|c|}
\hline 研究分野 & \multicolumn{2}{|c|}{ 研究卜ピック } & 研究対象 \\
\hline Marketing & $\begin{array}{l}\text { Consumer behavior } \\
\text { Branding } \\
\text { Sponsorship } \\
\text { Motivation } \\
\text { Fun ID } \\
\text { CSR }\end{array}$ & $\begin{array}{l}\text { Strategy } \\
\text { Brand community } \\
\text { Sexuality } \\
\text { Service quality } \\
\text { Sales } \\
\text { Organizational change }\end{array}$ & $\begin{array}{l}\text { Professional sport } \\
\text { Collage sport } \\
\text { Community sport } \\
\text { Elite sport } \\
\text { International sport } \\
\text { Youth sport } \\
\end{array}$ \\
\hline Management & $\begin{array}{l}\text { Organizational behavior } \\
\text { Leadership } \\
\text { CSR } \\
\text { Strategic Management } \\
\text { Volunteers } \\
\text { Diversity }\end{array}$ & $\begin{array}{l}\text { Organizational change } \\
\text { Human resource management } \\
\text { Work life } \\
\text { Organizational capacity } \\
\text { Learning }\end{array}$ & $\begin{array}{l}\text { Olympic sport } \\
\text { Amateur sport } \\
\text { Physical activity } \\
\text { Disability sport } \\
\text { Online community } \\
\text { School sport }\end{array}$ \\
\hline Socio cultural & $\begin{array}{l}\text { Diversity } \\
\text { Community }\end{array}$ & $\begin{array}{l}\text { Work life } \\
\text { Family }\end{array}$ & $\begin{array}{l}\text { Volunteers } \\
\text { Sport club }\end{array}$ \\
\hline Teaching / Learning & $\begin{array}{l}\text { Teaching strategies/methods } \\
\text { Professional development } \\
\text { Learning }\end{array}$ & $\begin{array}{l}\text { Mentoring } \\
\text { Teaching strategies }\end{array}$ & Immigrant sport \\
\hline Facilities / Events & $\begin{array}{l}\text { Event marketing } \\
\text { Operations } \\
\text { Facility marketing }\end{array}$ & $\begin{array}{l}\text { Sponsorship } \\
\text { Volunteers } \\
\text { Sustainability }\end{array}$ & \\
\hline Finance / Economics & Economics & Finance & \\
\hline Communication & $\begin{array}{l}\text { Social media } \\
\text { Media }\end{array}$ & Public relations & \\
\hline Sport for development & Social capital & & \\
\hline Governance / Policy & Governance & Policy & \\
\hline Sport development & Sport development & & \\
\hline Method & $\begin{array}{l}\text { Qualitative } \\
\text { Quantitative }\end{array}$ & Multilevel analysis & \\
\hline Law & Law & & \\
\hline
\end{tabular}

引き続き一層求められるのではないだろうか。

\section{2. 開発のためのスポーツ (Sport for development)}

開発のためのスポーツ（Sport for development；以下では「SFD」と略す）に関する研究は 14 題発表された。研究トピックはソーシャルキャピタル（Social capital）に関する発表が 1 題であ り、残り 13 題の研究トピックはその他（Others）であった。研究対象はコミュニティ・スポーツ (Community sport) が 6 題で最多、続いてユース・スポーツ（Youth sport）とその他（Others）が各 3 題発表された。

Svensson and Hambrick（2017）が指摘するように、SFDに関する研究はこれまで、プログラムの 実施前後にその効果を測定する内容が大半であった。しかし今大会では、SFD 関連組織内外の繋 がりに関する研究（Svensson and Hambrick, 2017）やNF 等国内で中心となるスポーツ組織が SFD 組織をどう捉えているのかに着目した研究 (Clutterbuck and Doherty, 2017)、SFD 組織のリーダーシ ップに関する研究 (Peachey at el., 2017) 等、研究対象がより多様となった。

研究の幅が広がる一方で、SFD（Sport For Development）やSDP（Sport for Development \& Peace)、SD（Sport Development）と言葉の使い分けは多様であり、同義でも研究毎に異なる単語で 
の表現が散見された。ただ、研究分野としては緒に就いたばかりであり、研究の蓄積と共に用語や 定義の統一が今後期待される。

\section{学会大会の運営・プログラムについて}

\section{1. 学会スケジュール管理アプリ" Yapp" について}

今大会では、参加者がプログラムスケジュールを容易に把握できるようにするため、モバイルデ バイス用のアプリケーション”Yapp” が導入された。このアプリケーションには、基調講演や編集 委員会議等の学会全体スケジュールを確認できる ”Schedule at a Glance” 機能（図 1）や、発表タイ トルや発表者といった詳細な情報とそのスケジュールが盛り込まれた”Academic Program Schedule" 機能（図 2）が含まれている。また、自分だけの学会スケジュールが ”My Schedule”機能（図 3） によって作成可能となり、聞きたい研究の抄録を各個人のスマートフォンやタブレット上で閲覧可 能となった。なお、大会参加受付時に配布される冊子には、大会スケジュールと発表タイトル及び 発表者のみが記載されている。学会用アプリケーションに関するメールが学会前に配信され、学会 員はメールに記載された URL リンクを介してダウンロードする、という流れである。多くの参加 者がアプリケーションを使用しており、好評を博している様子であった。

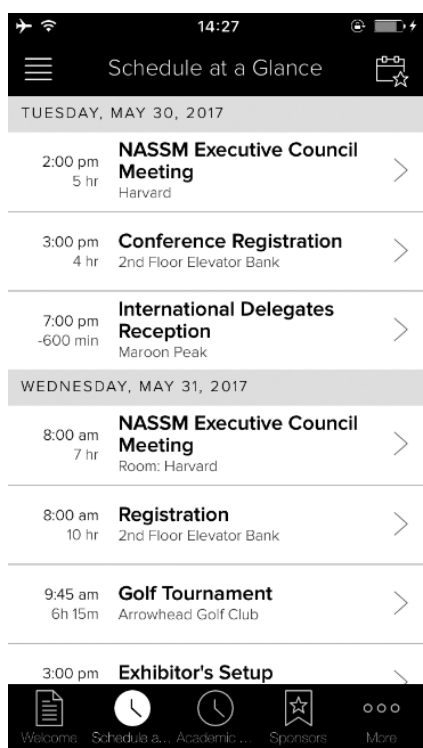

図 1 "Schedule at a Glance"機能

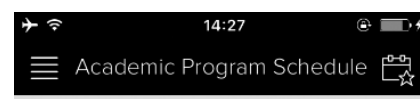

THURSDAY, JUNE 1, 2017

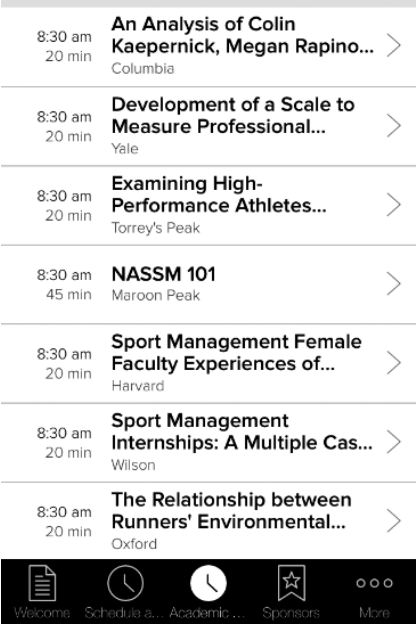

図 2 "Academic Program Schedule" 機能

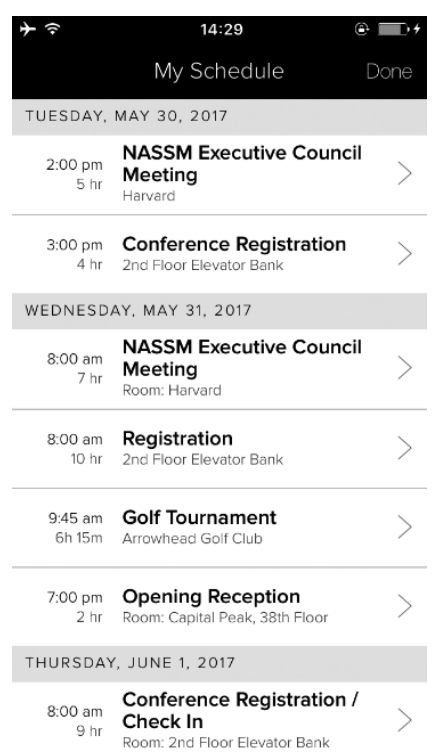

図 3 "My Schedule"機能挿入

\section{Student Mentor Initiative について}

NASSM において近年開催されている” Student Mentor Initiative”というプログラムについて紹介 したい。本プログラムは、学部生や修士課程の学生を対象に、主に博士課程の学生や若手研究者と の繋がりを学会期間中に提供するという、学生委員会主催のイベントである。参加したい学生は、 自分の所属や学年、関心のある研究分野を事前に登録すると、学生委員会が行ったマッチング結果 に基づいて、学会期間中に若手研究者や博士課程の学生と直接話すことができる機会を設けてくれ る。自身の研究はもちろんのこと、進路選択の相談にも非常に有用であるため、特に北米への進学 


\section{おわりに}

本稿では、北米スポーツマネジメントの研究動向として、2017 年度大会で発表件数が最も多か ったマーケティング分野、及び、近年注目を集める開発のためのスポーツ分野を紹介した。また、 学術的な研究発表だけでなく、学会大会の運営やプログラムについても特徴的な点を紹介した。こ れらの情報提供が、多くの研究者や学生にとって、有益となれば幸いである。

2018 年の NASSM は、カナダのノバスコシア州ハリファックスにて 2018 年 6 月 5 日から 6 月 9 日にかけて開催される予定である。ハリファックスはカナダ大西洋岸地方最大の文化・経済都市で あり、マリンスポーツが盛んな地域である。日本からも多くの研究者や学生が参加され、活発な情 報収集や情報交換がされることを期待したい。

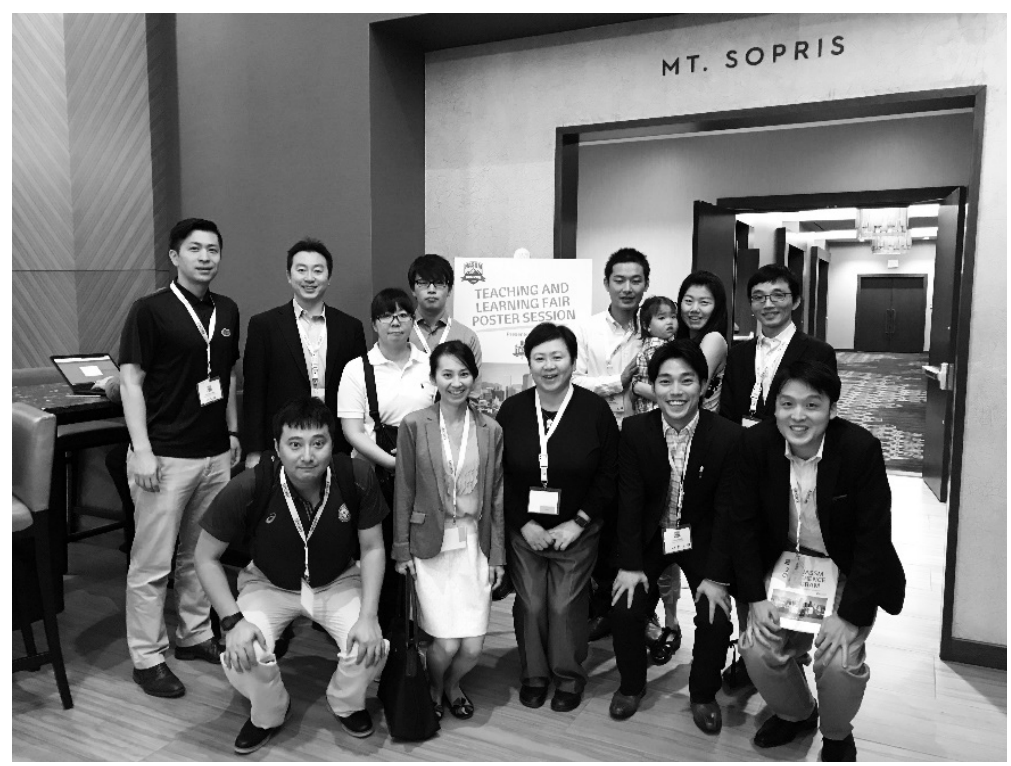

図 4 日本人参加者で記念撮影

\section{【引用文献】}

Clutterbunk, R. and Doherty, A. (2017) Sport for Development in Canada: Perspectives from National Sport Organization Leaders. 20-minute oral presentation at the $32^{\text {nd }}$ North American Society for Sport Management Conference, Denver, CO, USA.

Hanna, C., Greenwell, T. C. and Hambrick, M. (2017) Evvaluating Minor League Baseball Social Identity and Brand Equity. 20-minute oral presentation at the $32^{\text {nd }}$ North American Society for Sport Management Conference, Denver, CO, USA.

Heere, B., Breitbarth, T, Xing, X., Jones, A., Paramio-Salcines, J. L., Yoshida, M. and Derom, I. (2017) Using Hallmark Sport Events to Internationally Brand Your City: Measuring the Effects of the Tour de France on the Brand of the City of Utrecht in Nine Different Nations. 20-minute oral presentation at the $32^{\text {nd }}$ North American Society for Sport Management Conference, Denver, CO, USA.

Lee, M., Yu, H. and Lee, D. H. (2017) Sport Brand Extension Evaluations: A Case study of Nike Golf and TaylorMade Golf. 20-minute oral presentation at the $32^{\text {nd }}$ North American Society for Sport Management Conference, Denver, 
CO, USA.

Medeiros, S. and Chard, C. (2017) Understanding the Brand Associations Attached to U sports by Former NCAA \& Current U Sports Student-Athletes. 20-minute oral presentation at the $32^{\text {nd }}$ North American Society for Sport Management Conference, Denver, CO, USA.

Peachey, J. W., Burton, L. and Wells, J. (2017) Comparing Servant and Transformational Leadership and Their Relationship to Organizational Effectiveness in the Sport for Development and Peace Context. 20-minute oral presentation at the $32^{\text {nd }}$ North American Society for Sport Management Conference, Denver, CO, USA.

Svenson, P. and Hambrick, M. (2017) NOLA Sport for Community Coalition: A Mixed-Method Study of the Nature of Inter-Organizational Relationships in a Collaborative Sport for Development Initiative. 20-minute oral presentation at the $32^{\text {nd }}$ North American Society for Sport Management Conference, Denver, CO, USA. 